\title{
Biochemical Characteristics, Antimicrobial and Mutagenic Activity in Organically and Conventionally Produced Malus domestica, Annurca
}

\author{
Florinda Fratianni, Alfonso Sada, Luigi Cipriano, Annamaria Masucci and Filomena Nazzaro*
}

Istituto di Scienze dell'Alimentazione-CNR, via Roma 52, 83100, Avellino, Italy

\begin{abstract}
Total polyphenols content and a partial phenolics composition from pulp and peel of organically and conventionally produced Malus domestica, Annurca were investigated. Furthermore, the antimicrobial effect of these compounds against useful and pathogen microorganism was examined. Finally, their mutagenic activities were evaluated. Organically grown apples showed a greater content of polyphenols, both into the pulp and the peel. The distribution of polyphenols was different between the two types of fruit, the organic fruit showing a more concentration of them, mainly into the peel extracts. The antimicrobial activity was also different: the conventionally produced samples showed a good inhibitory effect against Bacillus cereus, the organic peel revealed in addition a good inhibitory effect against Escherichia coli 0157:07. The results demonstrated a probable relationship between the phenolic composition and distribution in the extracts and the antimicrobial effect. The Ames test did not reveal the presence of an evident mutagenic activity in the conventional extracts. The antimutagenic activity was more evident in the organic extracts.
\end{abstract}

Keywords: Ames test, Annurca, Antimicrobial, phenolics, HPLC, Malus domestica.

\section{INTRODUCTION}

Apples are worldwide diffused fruit with many health beneficial effects, mostly due to the presence of phenolic compounds. Polyphenols are common secondary metabolites of plants, with a well known putative role in protection against the infection by plant pathogens [1]. Apples also ranked the second for total content of phenolic compounds, including quercetin, catechin, phloridzin and chlorogenic acid, all of which are strong antioxidants, and thus capable of counterbalancing free radical activities that may cause cell injuries [2-3].

The phytochemical composition varies greatly among different varieties of apples. The importance of plants as natural sources of phenolics is supported by epidemiological studies, which generally link the consumption of polyphenols with a reduced risk of some cancers, cardiovascular disease, asthma, and diabetes. Furthermore, these metabolites show other interesting biological properties, such as anti-inflammatory, antioxidant, antiviral and antimicrobial activities [4-5]. Interest in the antimicrobial properties of phenolics is strengthened by suggestions that they affect the behaviour of pathogenic bacteria in foods derived from plants; indeed, their use as natural additives in food industry is increased since last years [6].

Annurca apple (Malus domestica, Annurca) is one of the most important and ancient cultivars in Campania region, Southern Italy, and it is the unique to have received from the European Council the "Protected Geographical Indication", related to the preservation of local and characteristics agriculture commodities (CEE rule nr 2081, 1992). Typical elements which differentiate the Annurca from the other varieties are the traditional method of growing and manufacturing

*Address correspondence to this author at the Istituto di Scienze dell'Alimentazione-CNR, via Roma 52, 83100, Avellino, Italy; Tel: +39 0825 299102; Fax: +39 0825781585; E-mail: mena@ isa.cnr.it as well as its morphological aspect of its pomace. Fruits are treated in a particular manner to obtain their typical redness. After harvest, they are placed for about 30 days on a layer of straw on the soil and daily sprayed with water. When the surfaces of fruits become red, apples are manually turned so to be homogeneously redden. Typical Annurca is an apple of middle size, with a weight of about $100 \mathrm{~g}$; its peel has a dark red colour with yellow areas and, on the top, a characteristic and no more wide rusty area. Pulp is white, crunchy, sweet and lightly acidic, with a pleasant aroma and taste. Many studies were performed on different aspects of its biology and biochemistry, concerning texture composition, aroma and the identification of several polyphenols [7-9].

The aim of our work was to highlight some biochemical, microbial and genotoxic characteristics of extracts from organically and conventionally produced Annurca apple. In essence, we examined the polyphenol content and performed a partial composition in polyphenols present in pulp and peel as well the antimicrobial activity of these extracts against unwanted, pathogen or lactic acid bacteria. Finally, we analysed their in vitro mutagenic properties.

\section{MATERIALS AND METHODS}

\section{Standards and Reagents}

All standards were obtained from Sigma Chemicals (St Louis, MO). Acetonitrile and trifluoroacetic acid were obtained from Carlo Erba Reagenti (Milan, Italy). Acetone, methanol, ethanol and ethyl acetate were purchased from Sigma Chemicals. All reagents were of analytical grade.

\section{Fruit Material}

The experiments were performed on commercial samples of organically and conventionally produced samples of Malus domestica, Annurca. Immediately on arrival in laboratory, fruits were washed; pulp and peel were accurately separated and stored at $-26^{\circ} \mathrm{C}$ until the extraction of polyphenols. 


\section{Preparation of Extracts}

The extracts were prepared following partially the method of Fratianni, Tucci, De Palma, Pepe \& Nazzaro [10]. Briefly, frozen samples were incubated for $1 \mathrm{~h}$ at $4^{\circ} \mathrm{C}$ in 5 volumes of acetone: ethanol: methanol (70:15:15), avoiding direct contact with light, concentrated by drying and resuspended in methyl alcohol. The concentrates were filtersterilized $(0.22 \mu \mathrm{m}$ membrane $)$ and kept at $-26^{\circ} \mathrm{C}$.

\section{Total Phenolic Assay}

Total polyphenol content was measured using the Folin Ciocaltetau colorimetric method [11]. To $800 \mu \mathrm{L}$ of deionised water, $50 \mu \mathrm{L}$ of Folin Ciocalteau's phenol reagent and a volume of sample ranging from 10 to $50 \mu \mathrm{L}$ were added and accurately mixed. After $1 \mathrm{~min}, 100 \mu \mathrm{L}$ of $20 \%$ sodium carbonate solution was added and mixed. Deionised water was then added up to a volume of $1 \mathrm{~mL}$. The solution was carefully mixed and total phenols were spectrophotometrically estimated at $765 \mathrm{~nm}$ (DU-Beckman, USA) after $2 \mathrm{~h}$ incubation. Quantification was based on the standard curve generated with quercetin. All determinations were carried out in triplicates.

\section{Chromatographic Analysis}

All standards used in the experiments were accurately weighed, dissolved in methanol and treated with ultrasonic waves for $10 \mathrm{~min}$. The calibration curves were generated with concentrations ranging from 0.01 to $0.5 \mathrm{mM}$ of chlorogenic acid, coumaric acid, ferulic acid, caffeic acid, catechin, epicatechin, phloridzin. The chromatographic analysis of the apple extracts was performed [10] by RP-HPLC, using a Gold System apparatus equipped with an UV detector (Beckman, CA, USA). A Khromasyl KR 100-5 C-18 column $(25 \mathrm{~cm} \times 4.6 \mathrm{~mm})$ at room temperature was used for this analysis. The mobile phase included HPLC pure water (containing $0.1 \%$ trifluoroacetic acid, solvent A) and 95\% acetonitrile (containing $0.1 \%$ trifluoroacetic acid, solvent $\mathrm{B}$ ) in the following gradient system: initial $10 \% \mathrm{~B}$, linear gradient to $50 \% \mathrm{~B}$ in $30 \mathrm{~min}$, linear gradient to $100 \% \mathrm{~B}$ in $5 \mathrm{~min}$, hold at $100 \% \mathrm{~B}$ for $2 \mathrm{~min}$, decreasing gradient to $10 \% \mathrm{~B}$ in $2 \mathrm{~min}$ and coming back to the initial steps $10 \% \mathrm{~B}$ for $10 \mathrm{~min}$. The total pre, running and post running time was $54 \mathrm{~min}$. The flow rate was $1 \mathrm{ml} / \mathrm{min}$, the injection volume was $20 \mu \mathrm{l}$, and the detection wavelength was set at $280 \mathrm{~nm}$.

\section{Microorganisms and Culture Media}

Lactobacillus casei DSM 9595, Lactobacillus fermentum DSM 20052, Lactobacillus acidophilus DSM 20079, Lactobacillus bulgaricus DSM 20081, Lactobacillus rhamnosus DSM 20711, Escherichia coli DSM 8579, Escherichia coli EC 101, Bacillus cereus DSM 4313, Bacillus cereus DSM 4384, and Bacillus cereus GN 105 were grown for $18 \mathrm{~h}$ into specific growth media: Lactic acid bacteria in MRS broth (OXOID), Escherichia coli and Bacillus cereus in Nutrient Broth (OXOID).

\section{Antimicrobial Activity}

Antimicrobial activity was performed by the inhibition halo test on agar plates. The microbial suspensions $\left(1 \times 10^{8}\right.$ $\mathrm{CFU} / \mathrm{ml}$ ) were uniformly spread onto the specific solid media plates. Sterile Whatman $\mathrm{n}^{\circ} 1$ filter paper discs $(5 \mathrm{~mm}$ in diameter) were individually placed on the inoculated plates and impregnated with polyphenolic extracts $(38 \mu \mathrm{mol})$. After 30 min standing in sterile conditions at room temperature, plates were incubated for $24-48 \mathrm{~h}$ at $37^{\circ} \mathrm{C}$, depending on the strain. The diameter of the clear zone shown on plates was accurately measured and expressed in millimetres as its antimicrobial activity. Sterile deionised water was used as negative control; the standard antibacterial agent, chloramphenicol $(8 \mu \mathrm{g})$, was used as a positive control [12]. All antimicrobial experiments were performed in triplicate using independently- prepared plates.

\section{Mutagenicity Test}

For mutagenicity assay on extracts from Annurca apple, the Ames assay was performed [13] by using the Salmonella typhimurium histidine-requiring strains TA98 and TA100, purchased from Molecular Toxicology Inc. (Moltox ${ }^{\mathrm{TM}}$, Annapolis, MD, USA). Strains were aerobically grown at $37^{\circ} \mathrm{C}$ in Nutrient Broth $n^{\circ} 2$ (OXOID) supplemented with ampicillin. The test was carried out by addition of $0.1 \mathrm{ml}$ of the overnight bacterial culture, polyphenol extracts $(32.2 \mathrm{mmol})$, and $0.5 \mathrm{ml}$ phosphate buffer $(0.1 \mathrm{M}, \mathrm{pH} 7.4)$ to $1.8 \mathrm{ml}$ of molten agar; the mixture was immediately plated onto minimal medium agar plates (previously added with $0.2 \mathrm{ml}$ of sterile $0.5 \mathrm{mM}$ Bio-His) and incubated at $37^{\circ} \mathrm{C}$ for $48 \mathrm{~h}$ in the dark. Positive and negative (spontaneous revertants) controls in the presence and absence of the diagnostic mutagen were included. As positive controls, the direct acting mutagens nitrofluorene was used for strain TA 98 and sodium azide for strain TA 100; the indirect acting mutagen was 2-aminoantracene. Metabolic activation was achieved $[13,14]$, by a polychlorinated biphenyl mixture Aroclor 1254-induced S9 homogenate $(0.7 \mathrm{nmol}$ cytochrome $\mathrm{P} 450 / \mathrm{mg}$ protein) prepared from male Sprague-Dawley rats and incorporated in the S9 mixture (Moltox ${ }^{\mathrm{TM}}$, Annapolis, MD, USA). All tests were conducted in triplicate and the results averaged.

\section{Antimutagenicity Testing}

Antimutagenicity testing procedures were essentially as described by Ames and coworkers [13]. Briefly, the mutagen standard was added to the mixture of pulp or peel apple extract $(32.2 \mathrm{mmol})$, bacterial culture, with $\mathrm{S} 9 \mathrm{mix}$ (indirect test) or phosphate buffer (direct test). After incubation for 30 $\min$ at $37^{\circ} \mathrm{C}$, the mixture was added to $2.0 \mathrm{ml}$ of molten agar and plated as above. Positive and negative controls were also included in each assay. His+ revertants were counted after 48 $\mathrm{h}$ of incubation at $37^{\circ} \mathrm{C}$. The antimutagenic activity was expressed as percentage of inhibition: [1-(T -S/M-S)] $\cdot 100$, where $\mathrm{T}$ is the number of revertants/plate in the presence of mutagen and the test sample, $M$ is the number of revertants/plate in the positive control and $S$ is the number of spontaneous revertants/plate [15].

\section{RESULTS AND DISCUSSION}

\section{Total Phenol Content}

The polyphenol content of pulp and peel of organic and conventional Annurca samples is presented in Table 1. Pulp and peel showed a different phenolic content: the value evidenced in the peel was found to be 14 times superior than in corresponding pulp. Because the apple peels contain more antioxidant compounds, they may have higher antioxidant activity and higher bioactivity than the apple pulp. Research 
demonstrated that apples without the peels had less antioxidant activity than apples with the peels. Apples with the peels were also better able to inhibit cancer cell proliferation when compared to apples without the peels [5]. Other studies have shown that apple peels contain anywhere from two to six times (depending on the variety) more phenolic compounds than in the flesh. The antioxidant activity of these peels is also much greater, ranging from two to six times greater in the peels when compared to the flesh, depending on the variety of the apple [16]. By focusing on the phenols in two types of Annurca apple, we found that the organically grown variety contained many more phenols in contrast to those grown in a conventional way. A different content in polyphenols was also reported by Veberic et al. [17] and Hecke et al. [18], which studied several organic and integrated varieties of apple. Generally, the content of polyphenols may be expected in vegetable organisms also as reaction against biotic or abiotic stress. The application of pesticides and fertilisers has been previously reported to affect the biosynthesis of phenolics in plants, substituting their action, so that conventionally grown plants generally show a phenol content lower than the same but organically grown varieties $[19,20]$.

Table 1. Total Polyphenolic Content in Pulp and Peel Extracts of Organic and Conventional Annurca Apple

\begin{tabular}{|c|c|c|}
\hline & Pulp & Peel \\
\hline \hline Organic apple & $66.88(3.67)$ & $941.17(26.77)$ \\
\hline Conventional apple & $12.29(3.98)$ & $267.09(19.53)$ \\
\hline
\end{tabular}

Data are mean values of 3 three determinations and are expressed as $\mu \mathrm{mol} / \mathrm{g}$ of fresh product. SD values are shown in parenthesis. For details: see materials and methods.

\section{HPLC Analysis}

Usually, the compounds most commonly found in apple peels consist of the catechin, epicatechin, procyanidins, chlorogenic acid, phloretin glucoside (phloridzin). In the apple flesh, there is some catechin, procyanidin, epicatechin, and phloridzin but these compounds are found in much lower concentrations than in the peels [21]. Above all, we analysed the polyphenols ferulic, chlorogenic $p$-coumaric and caffeic acid; the content of flavan-3-ols catechin and epicatechin as well as phloridzin was also investigated. The chromatographic analysis of some polyphenols is reported in
Table 2. Generally, organic Annurca showed a greater concentration of the polyphenols considered in our analysis. In the organic peel, the most abundant compounds were found to be catechin and epicatechin, as well as chlorogenic and caffeic acid, all of them generally present at a concentration of about or more than ten times in comparison to the conventional ones. On the contrary, the distribution o $p$-coumaric and ferulic acid was different, being the two polyphenols much more abundant in the conventional peel. The content of phloridzin was similar in the two extracts, being more abundant only in the organic peel extract. The presence of catechin and epicatechin, mainly in the organic apple, is important due to their strong antioxidant activity [22]. Furthermore, the good percentage of $p$-coumaric acid found in the organically and conventionally produced Annurca could be significant since this biomolecule has received a lot of attention in the recent years for its anti inflammatory in vivo properties [23]. Moreover, the high level of chlorogenic acid, observed mainly in organic fruits is of great meaning as in vivo studies have demonstrated the antioxidant and anticarcinogenic properties of this biomolecule, in general inefficiently absorbed in small intestine, but capable of providing higher yields of microbial metabolites, active compounds responsible for the biological properties attributed to dietary polyphenols [24-25]. The characterization of conventional and organic apple aimed at the identification of compounds developed by plant tissues as part of their defence mechanism was carried out by Lucarini et al. [26], which indicated higher levels of both polyphenols and specific phenolic acids, as p-coumaric and caffeic acid, in organically than in conventionally produced apples. On the whole, our results were similar relating to the total polyphenol content and to caffeic acid; they were also in agreement with the high content of chlorogenic acid found in apples [27] but could be shortly divergent with other researches performed on Annurca apple [9], in which the concentrations of some polyphenols, such as chlorgenic acid was different. Perhaps, this different content could be ascribable to a different time of harvesting of Annurca apple or to the different geographical area of growing.

\section{Antimicrobial Test}

Since many years, phenolic compounds became the subject of anti-infective research, due to their antibacterial, antifungal and antiviral activity [28-31]. They can have an effect on growth and metabolism of bacteria, activating or inhibit-

Table 2. Chromatographic Results of Polyphenols Analysis in Pulp and Peel Extracts of Conventionally and Organically Grown Annurca Apple

\begin{tabular}{|c|c|c|c|c|}
\hline Chlorogenic acid & 9 & 18 & 11 & 118,9 \\
\hline p-Coumaric acid & 1,4 & 100,05 & 2 & 70,9 \\
\hline Epicatechin & 16 & 35,2 & 19,15 & 305,2 \\
\hline Phloridzin & 7,19 & 5,28 & 5,56 & 16,88 \\
\hline
\end{tabular}

The data are expressed as $\mu \mathrm{mol} / \mathrm{g}$ of fresh product. Values represent the mean of three different analyses of three independent samples. For details: see materials and methods 
ing microbial growth according to their constitution and concentration [32]. We have analysed the effect of different concentrations (from 9 to $38 \mu \mathrm{mol}$ ) of apple Annurca extracts on different useful ( $L b$. acidophilus, Lb. bulgaricus, Lb. casei, Lb. fermentum, Lb. rhamnosus) or pathogen microorganisms of agro-food or human interest, such as $B$. cereus, an aerobic spore-former commonly found in raw and processed foods, which determines several cases of foodborne illnesses, and the EHEC entero-haemorragic E. coli DSM 8579, that causes serious cases of food poisoning. None of apple extracts assayed gave positive results against the 6 strains of lactic acid bacteria. The conventional extracts determined the formation of inhibition halos, having a diameter of about $10 \mathrm{~mm}$, only against the three strains of $B$. cereus GN105, DSM 4313 and DSM 4384, at $38 \mu \mathrm{mol}$; a more marked action was evident only against $B$. cereus GN105 with the maximum of extracts tested (inhibition halo $=18 \mathrm{~mm}$ ). The extracts from the organically grown apple exhibited a clear antimicrobial activity, both against the strains of B. cereus and against the two strains of E. coli. In this case, peel was found to possess a discrete activity, the inhibition halos increasing from $6 \mathrm{~mm}$ (with $19 \mu \mathrm{mol}$ of extracts tested on B. cereus DSM 4313) to $13 \mathrm{~mm}$ of diameter (against $E$. coli $\mathrm{EC} 101$ treated with $38 \mu \mathrm{mol}$ ). The effectiveness found against the pathogenic microorganism $E$. coli DSM 8579 serotype O157:H7, an EHEC enterohaemorragic E. coli, of worldwide interest for the human health, can be considered of promising importance, as this strain produces verocytotoxins, and causes haemorrhagic colitis and haemo- lytic uremic syndrome. In our experiments, the inhibition halos showed a diameter ranging from $7 \mathrm{~mm}$ to $11 \mathrm{~mm}$ ) (by testing $19 \mu \mathrm{mol}$ and $38 \mu \mathrm{mol}$, respectively). The inhibition halo caused by chloramphenicol was of $28 \mathrm{~mm}$. Previous reports on the antimicrobial activity of phenolic acids were described, relatively to the growth inhibition of specific polyphenols and to the different species of apple: a slight or no activity was found, by using extracts from the whole fruit of a Finnish apple variety, against $S$. aureus, $S$. epidermidis, B. subtilis, M. luteus, E. coli [33]; on the contrary, an effective activity of extracts mainly from Granny Smith apple, and less from Royal gala, was observed against E. coli, $P$. aeruginosa and $S$. aureus [34]. Our results reported, for the first time, a good antimicrobial activity exhibited from Annurca extracts. However, the different activity of organic and conventional apples against the pathogenic bacteria tested, let us hypothesise a strong relationship between content and distribution of phenolics and antibacterial effect.

\section{Mutagenicity Assay}

It is well known that a large number of compounds that are in vivo carcinogenic also produce mutagenicity in the in vitro Ames test of mutagenicity, producing a direct or an indirect (promutagenic) activity [13]. Table $\mathbf{3}$ shows the results obtained from the Ames test by using S. typhimurium TA 98 (Table 3A) and S. typhimurium TA 100 His- strains (Table 3B) to detect the direct and indirect mutagenic

Table 3. Enumeration of His+ Revertants in Strain TA 98 (3A) and Strain TA 100 (2B) in the Ames Test

Table 3A.

\begin{tabular}{|l|c|c|}
\hline \multicolumn{1}{|c|}{ TA 98 His + Spontaneous Revertants (Normal Values: 20-50) } & $\begin{array}{c}\text { CFU/Plate - S9 } \\
\text { Mean (SD) }\end{array}$ & $\begin{array}{c}\text { CFU/Plate + S9 } \\
\text { Mean (SD) }\end{array}$ \\
\hline \hline TA 98 Negative control (with phosphate buffer) & $34(6.50)$ & $40(11.01)$ \\
\hline TA 98 Positive control (with mutagen standard) & $266(13.01)$ & $200(18.03)$ \\
\hline TA 98 + extract from peel of organic apple (32.2 mM) & $24(3.60)$ & $20(10.01)$ \\
\hline TA 98 + extract from pulp of organic apple (32.2 mM) & $25(4.58)$ & $21(4.72)$ \\
\hline TA 98 + extract from peel of conventional apple $(32.2 \mathrm{mM})$ & $30(7.81)$ & $154(29.46)$ \\
\hline TA 98 + extract from pulp of conventional apple $(32.2 \mathrm{mM})$ & $39(4.58)$ & $152(14.00)$ \\
\hline
\end{tabular}

Table 3B.

\begin{tabular}{|c|c|c|}
\hline TA100 His + Spontaneous Revertants (Normal Values: 80-200) & $\begin{array}{c}\text { CFU/Plate -S9 } \\
\text { Mean (SD) }\end{array}$ & $\begin{array}{c}\text { CFU/Plate + S9 } \\
\text { Mean (SD) }\end{array}$ \\
\hline TA 100 Negative control (with phosphate buffer) & $135(19.31)$ & $110(21.59)$ \\
\hline TA 100 Positive control (with mutagen standard) & $366(17.61)$ & $400(21.93)$ \\
\hline TA $100+$ extract from peel of organic apple $(32.2 \mathrm{mM})$ & $114(9.86)$ & $90(10.81)$ \\
\hline TA $100+$ extract from pulp of organic apple $(32.2 \mathrm{mM})$ & $95(7.93)$ & $105(24.26)$ \\
\hline TA $100+$ extract from pulp of conventional apple $(32.2 \mathrm{mM})$ & $84(6.55)$ & $193(13.52)$ \\
\hline
\end{tabular}

The data represent the mean of three independent experiments. Each experiment was performed in triplicate. SD values are shown in parenthesis. CFU: Colony Forming Units. For details: see materials and methods. 


\section{A. Antimutagenicity Tests on Conventional Annurca apple}

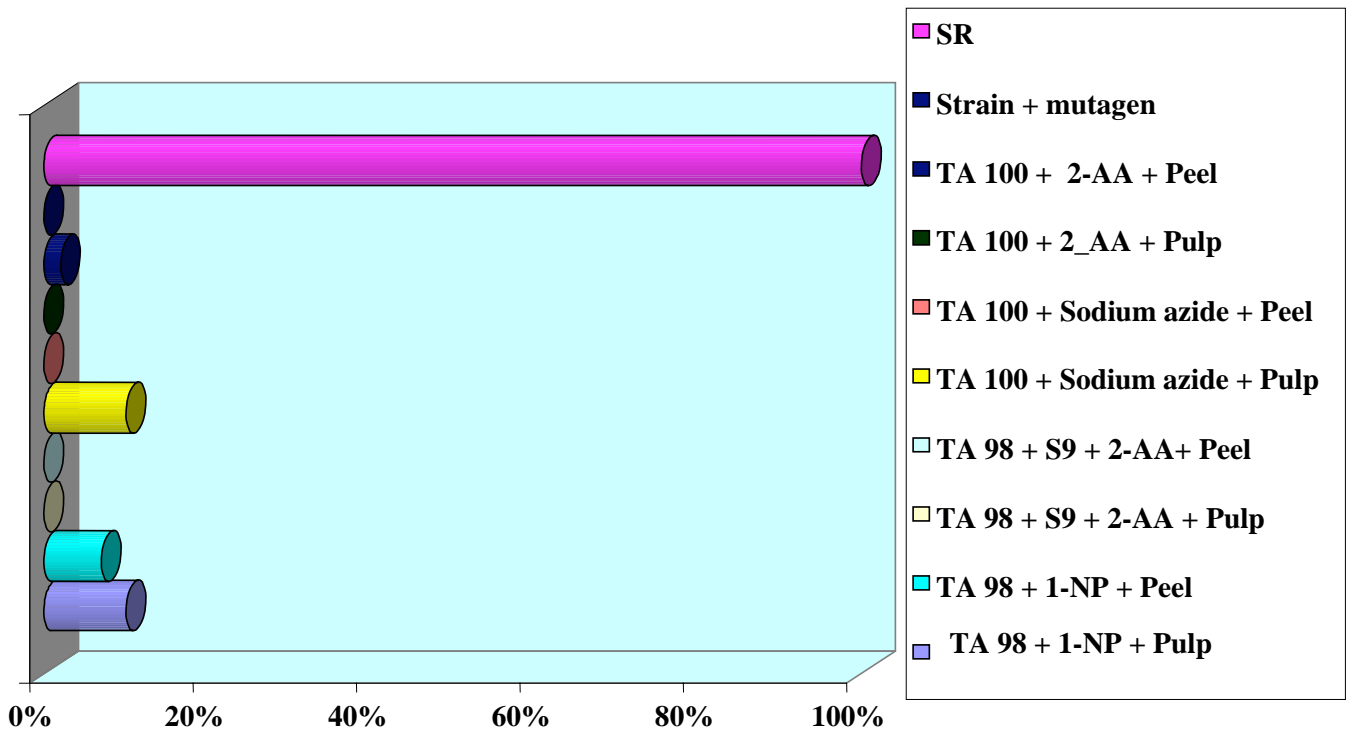

B. Antimutagenicity Test on Organic Annurca Apple

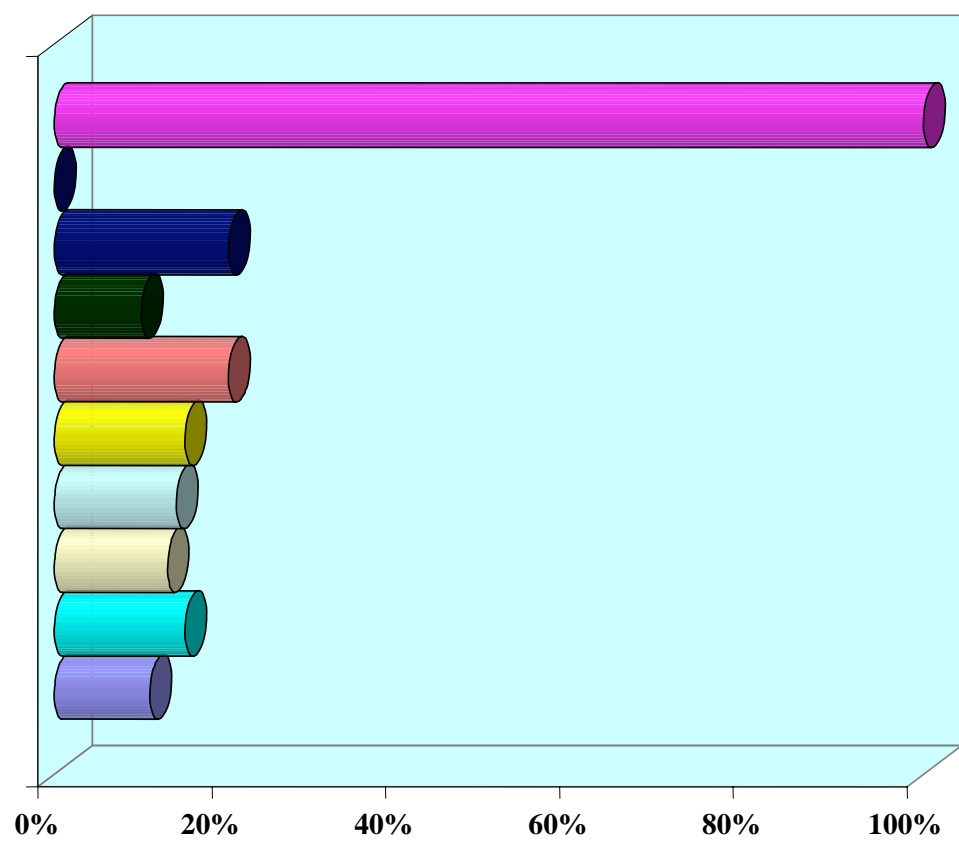

$\square$ SR
Strain + mutagen
$\square$ TA 100 + 2-AA + Peel
$\square$ TA 100 + 2_AA + Pulp
$\square$ TA 100 + Sodium azide + Peel
$\square$ TA 100 + Sodium azide + Pulp
$\square$ TA 98 + 2-AA+ Peel
$\square$ TA 98 + 2-AA + Pulp
$\square$ TA 98 + 1-NP + Peel
$\square$ TA 98 + 1-NP + Pulp

Fig. (1). Antimutagenic activity of extracts from pulp and peel of conventional (A) and organic (B) apple, Annurca, against nitrofluorene (S9) and 2-aminoanthracene (+S9) induced mutagenesis in S. typhimurium TA98 and sodium azide (-S9) and 2-aminoanthracene (+S9) induced mutagenesis in S. typhimurium TA100. The results are the mean of three independent experiments and are presented as percentage of inhibition of mutagenesis. Each experiment was performed in triplicate. SR: Spontaneous Revertants. For details: see materials and methods. 
activity of pulp and peel extracts when a very high concentration $(32.2 \mathrm{mmol})$ of polyphenols was used. The extracts from conventional apple showed, in the direct test with TA 98 , values very similar to those recorded in absence of the mutagen standard, with a number of CFU/plate ranging from 30 to 39. However, in the indirect test, the number of CFU/plate, even if not reaching he values of the positive control, was higher if compared to the negative control (Table 3A); the same trend was observed when the extracts from pulp and peel from conventional apples were put in contact with S. typhimurium TA 100, both in the direct an in the indirect test (84-85 versus 135, and 198-185 versus 110 CFU/plate respectively, Table 3B). The organic extracts gave values always lower to the positive control and very similar to the negative control both in the direct test and in the indirect test with TA 98, (Table 3A,B). In some occasions, values of $\mathrm{CFU} /$ plate were also lower than the negative control (Table 3A). So, the Annurca apple extracts did not induce evident gene mutations, this behaviour being more marked manner for the organic extracts and less evident for the conventional ones, probably due to a different concentration and distribution of polyhenols between conventional and organic apple and between the different portion of the fruit; this is in agreement with previous works, which demonstrated the no toxicity of some polyphenols, such as catechins and procyanidins in mutagenicity test, and chlorogenic acid, which is the main phenolic acid derivative in apple [35-37].

\section{Antimutagenicity Test}

Fig. (1) represents the inhibitory effects exhibited by extracts of conventional (1A) and organic (1B) pulp and peel extracts against nitrofluorene (direct acting) and 2aminoanthracene (indirect acting) mutagenesis (for S. typhimurium TA98) and sodium azide (direct acting) and 2aminoanthracene (indirect acting) mutagenesis. Organic samples showed always a whole inhibitory effect against the mutagen standard, with percentages of inhibition until $20 \%$ for peel. The extracts from conventionally produced apples did not cause such an effect in so evident way, giving rare percentage of inhibition (until 15\%) only for pulp. The different action performed by organic and conventional apples Annurca could be ascribable not only to the different practise of growth, but also to the different concentration of some phenolics, such as chlorogenic acid, catechin and epicatechin, with well known antimutagenic activity [36,37], which we found to be more concentrated in the organic apple.

\section{CONCLUDING REMARKS}

Taken together, this study demonstrated a difference, in terms of biochemical distribution and concentration of some polyphenols of interest, and a different antimicrobial behaviour of phenolic extracts against some pathogen bacteria, between organic and conventional Annurca apple. Use of peel extracts from organically grown Annurca apples could be considered of great pharmacological interest, due to their antimicrobial activity against some food-borne bacteria such the enthemorragic E. coli 0157:07. The results did not reveal the presence of components in conventional Annurca apples that could be clearly mutagenic in the Ames test, thus indicating that the conventional growing practise did not lead the formation of mutagenic compounds. However, the different behaviour observed from the extracts from conventional fruit, mainly in the indirect test, a situation that mimics the contact between the possible promutagenic compounds and the human liver, let us hypothesise how the different composition and distribution of the phenolic compounds, could give a relative loss or modification of some constituents which could have initially acted as antimutagenic. Therefore, this hypothesis could be supported by the results observed in the antimutagenicity test. The organically produced fruit excludes the presence of some synthetic substances; it could also guarantee a more balanced product, in terms of polyphenol distribution, in possess also of better nutritional, biological and toxicological characteristics. Further studies are planned to deeply investigate the antimicrobial and antimutagenic activities of Annurca extracts and to attempt to isolate their bioactive components.

\section{AKNOWLEDGEMENTS}

This work was partially supported by the Centro Regionale di Competenza (CRdC) 'Produzioni Agroalimentari' in the framework of the project line A: "Mela Annurca per 1'industria" (P.O.R. 2000-2006, misura 3.16) of the Campania region, Italy. The authors greatly appreciate Anna Arcella, Maria Antonietta Belisario, Beatrice De Giulio, Gino Naclerio and Giovanni Pontecorvo for their kind assistance.

\section{REFERENCES}

[1] Walker JRK. Antimicrobial compounds in food plants. In (V. M. Dillon, \& R. G. Board Eds), Natural antimicrobial systems and food preservation, 1994; pp. 181-204. Wallingford: CAB International.

[2] Bravo L. Polyphenols: chemistry, dietary sources, metabolism, and nutritional significance. Nutr Rev 1998; 11: 317-333.

[3] Tedesco I, Russo GL, Nazzaro F, Russo M, Palumbo R. Antioxidant effect of red wine anthocyanins in normal and catalase inactive human erythrocytes. J Nutr Biochem 2001; 12: 505-511.

[4] Kanner J, Frankel E, Granit R, German B, Kinsella JE. Natural antioxidants in grapes and wine. J Agric Food Chem 1994; 42: 6469.

[5] Eberhardt MV, Yong Lee C, Hai Liu R. Antioxidant activity of fresh apples. Nature 2000; 405: 903-904.

[6] Beuchat LR. In: Natural antimicrobial systems and food preservation. V. M. Dillon, \& R. G. Board Eds. Wallingford: CAB International 1994; pp. 167-180.

[7] Lo Scalzo R, Testoni A, Genna A. Annurca apple fruit, a southern Italy apple cultivar:textural properties and aroma composition. Food Chem 2001; 73: 333-343.

[8] D'Abrosca B, Fiorentino A, Monaco P, Oriano P, Pacifico S. Annurcoic acid: a new antioxidant ursane triterpene from fruits of cv. Annurca apple. Food Chem 2006; 98: 285-290.

[9] Cefarelli G, D'Abrosca B, Fiorentino A, et al. Free-RadicalScavenging and antioxidant activities of secondary metabolites from reddened cv. Annurca Apple Fruits. J Agric Food Chem 2006; 54: 803-809.

[10] Fratianni F, Tucci M, De Palma M, Pepe R, Nazzaro F. Polyphenolic composition in different parts of some cultivars of globe artichoke (Cynara cardunculus L. var. scolymus (L.) Fiori) Food Chem 2007; 104: 1282-1286.

[11] Singleton VL, Rossi JA. Colourimetry of total phenolics with phosphomolibdicphosphotungstic acid reagent. Am J Enol Vit 1965; 16: 144-158.

[12] Dall'Agnol R, Ferraz A, Bernardi AP, et al. Antimicrobial activity of some Hypericum species. Phytomedicine 2003; 10: 511-516.

[13] Maron DM, Ames BN. Revised methods for the Salmonella mutagenicity test. Mutat Res 1983; 113: 173-215.

[14] Mortelmans K, Zeiger E. The Ames Salmonella/microsome mutagenicity assay. Mutat Res 2000; 455: 29-60.

[15] Ong T, Wong WZ, Stewart JD, Brockman HE. Chlorophyllin: a potent antimutagen against environmental and dietary complex mixtures. Mutat Res 1986; 173: 111-115. 
[16] Wolfe K, Wu X, Liu RH. Antioxidant activity of apple peels. J Agric Food Chem 2003; 51, 609-614.

[17] Veberic R, Trobec M, Herbinger K, Hofer M, Grill D, Stampar F. Phenolic compounds in some apple cultivars (Malus domestica Borkh.) of organic and integrated production. J Sci Food Agric 2005; 85, 1687.

[18] Hecke K, Herbinger K, Veberic R, et al. Sugar-acid- and phenol contents in apple cultivars from organic and integrated fruit cultivation. Eur J Clin Nutr 2006; 60: 1136-1140.

[19] Lea AGH, Beech FW. The phenolic of ciders: effect of cultured conditions. J Sci Food Agric 1978; 29: 493-496.

[20] Daniel O, Meier MS, Schlatter J, Frischknecht P. Selected phenolic compounds in cultivated plants: ecologic functions, health implications, and modulation by pesticides. Environ Health Perspect 1999; 107: 109-114.

[21] Boyer J, Hai Liu R. Apple phytochemicals and their health benefits. Nutr J 2004; 3: 1-45.

[22] da Silva Porto P, Laranjinha J, de Freitas V. Antioxidant protection of low density lipoprotein by procyanidins: structure/activity relationships. Biochem Pharm 2003; 66: 947-954.

[23] Luceri C, Guglielmi F, Lodovici M, Giannini L, Messerini L, Dolara P. Plant phenolic 4-coumaric acid protects against intestinal inflammation in rats. Scand J Gastr 2004; 39: 1128-1133.

[24] Gonthier MP, Verny MA, Besson C, Remesy C, Scalbert A. Chlorogenic acid bioavailability largely depends on its metabolism by the gut microflora in rats. J Nutr 2003; 133: 1853-1859.

[25] Kim DH, Jung EA, Sohng IS, Han JA, Kim TH, Han M. Intestinal bacterial metabolism of flavonoids and its relation to some biological activities. Arch Pharm Res 1998; 21: 17-23

[26] Lucarini M, Carbonaro M, Nicoli S, et al. Endogenous markers for organic versus conventional plant products. In Agri-Food Quality II; Hagg M, Ahvenainen R, Evers AM, Tiilikkala K. Eds.; Royal Society of Chemistry: Great Britain, 1999; pp. 306-310.

[27] Escarpa A, Gonzalez M. High-performance liquid chromatography with diode array detection for the performance of phenolic com- pounds in peel and pulp from different apple varieties. J Chrom A 1998; 823: 331-337.

[28] Valsaraj R, Pushpangadan P, Smitt UW, et al. New anti-HIV-1, antimalarial, and antifungal compounds from Terminalia bellerica. J Nat Prod 1997; 60: 739-42.

[29] Dorman HJ, Deans SG. Antimicrobial agents from plants: antibacterial activity of plant volatile oils. J Appl Microbiol 2000; 88: 308316.

[30] Cushnie TPT, Lamb AP. Antimicrobial activity of flavonoids. Int J Antim Ag 2005, 26(5): 343-356.

[31] Fattouch S, Caboni PL, Coroneo V, et al. Antimicrobial Activity of Tunisian Quince (Cydonia oblunga Miller) Pulp and Peel Polyphenolic Extracts. J Agric Food Chem 2007; 55: 963-969.

[32] Alberto MR, Farias ME, Manca de Nadra MC. Effect of gallic acid and catechin on Lactobacillus hilgardii $5 \mathrm{w}$ growth and metabolism of organic compounds. J Agric Food Chem 2001, 49: 4359-4363.

[33] Rauha JP, Remes S, Heinonen M, et al. Antimicrobial effects of Finnish plant extracts containing flavonoids and other phenolic compounds. Int J Food Microbiol 2000; 56: 3-12.

[34] Alberto MR, Canavosio MAR, Manca de Nadra MC. Antimicrobial effect of polyphenols from apple skins on human bacterial pathogens. Electron J Biotechnol (on line). 2006 9, n.3. http://www. scielo.cl/scielo.php?script=sci_arttext\&pid=S0717-

$34582006000300006 \& \operatorname{lng}=\mathrm{es} \& \mathrm{nrm}=\mathrm{iso}>$. ISSN 0717-3458.

[35] Snjiman PW, Swanevelder S, Joubert E, Green IR, Gelderblom WC. The antimutagenic activity of the major flavonoids of rooibos (Aspalathus linearis): Some dose-response effects on mutagen activation-flavonoid interactions. Mutat Res 2007; 631:111-23.

[36] Stich HF, Rosin MP, Wu CH, Powrie WD. A comparative genotoxicity study of chlorogenic acid (3-O-caffeoylquinic acid). Mutat Res 1981; 90: 201-212.

[37] Geetha T, Garg A, Chopra K, Pal Kaur I. Delineation of antimutagenic activity of catechin, epicatechin and green tea extract. Mutat Res 2004; 556: 65-74. 